\title{
Hubungan Metode Persalinan dengan Penggunaan IUD Pascasalin di RSUD Panembahan Senopati Bantul
}

\author{
Eis Damayanti ${ }^{1}$, Irwan Taufiqurrachman ${ }^{2}$, Eugenius Phyowai Ganap ${ }^{3}$ \\ 1,2,3 Departemen Obstetri dan Ginekologi, Fakultas Kedokteran, Kesehatan Masyarakat, dan Keperawatan \\ Universitas Gadjah Mada, Yogyakarta, Indonesia \\ Korespondensi: eismulkan@gmail.com
}

Submisi: 26 Februari 2021; Revisi:18 Maret 2021; Penerimaan: 1 April 2021

\begin{abstract}
Background: Postpartum is an important period for starting contraception, but it is still underutilized, especially for postpartum intrauterine device (IUD). This is indicated by the use of postpartum IUD only $14.06 \%$ of all postpartum contraceptive methods. The number of abdominal delivery has increased significantly lately, reaching $29.6 \%$ in Indonesia. Increased rates of cesarean section were not followed by an increase in postpartum IUD use. Even though the chances of postpartum IUD insertion during cesarean caesarean delivery are greater.

Objective: This study aims to find out the association between mode of delivery and postpartum IUD insertion in Panembahan Senopati General Hospital.

Method: This study is an analytic study with cross sectional design. The study sample was taken from patients who gave birth in Panembahan Senopati General Hospital, data were collected by interview method. Chi square test and prevalence ratio were used for statistical analysis.

Results adn Discussion: This study recruited 260 subjects, 161 (61.92\%) vaginal deliveries and 99 (38.08) caesarean section. The total number of postpartum IUD insertion was $128(49.23 \%)$. The caesarean section had a significant relationship with postpartum IUDs insertion (p 0.000; PR 1.49; Cl 1.19-1.89). Other factors that significantly influence postpartum IUDs insertion were previous history of long-term contraceptive use (MKJP) ( 0.002 ; PR 1.68; Cl 1.38-2.06), JKN insurance ( $p$ 0.038; PR 1.71; Cl 1.04-2,80), and counseling ( $\mathrm{p} \mathrm{0.000;} \mathrm{PR} \mathrm{2.27;} \mathrm{Cl} \mathrm{1.36-3.78).} \mathrm{The} \mathrm{reason} \mathrm{most} \mathrm{of} \mathrm{the} \mathrm{subjects}$ refused postpartum IUDs insertion was fear of side effects (35\%).

Conclusion: The postpartum IUDs insertion was significantly higher in caesarean section than vaginal deliveries. Other factors that significantly influence the use of postpartum IUDs were the history of the use of the MKJP, JKN insurance and counseling.
\end{abstract}

Keywords: Postpartum IUD; mode of delivery; rate; vaginal delivery; caesarean section; IUD insertion

\begin{abstract}
ABSTRAK
Latar Belakang: Periode pascasalin merupakan masa yang penting untuk memulai kontrasepsi, namun masih kurang dimanfaatkan, utamanya untuk penggunaan IUD pascasalin. Hal ini ditunjukkan oleh penggunaan IUD pascasalin hanya 14,06\% dari keseluruhan metode kontrasepsi pascasalin. Angka seksio sesarea meningkat signifikan akhir-akhir ini, mencapai $29,6 \%$ di Indonesia. Peningkatan angka seksio caesarea (SC) tidak diikuti peningkatan penggunaan IUD pascasalin. Padahal peluang penggunaan IUD pascasalin pada persalinan abdominal/seksio sesarea lebih besar.

Tujuan: Penelitian ini bertujuan untuk melihat hubungan antara metode persalinan dengan penggunaan IUD Pascasalin di RSUD Panembahan Senopati. Metode: Penelitian ini merupakan penelitian analitik dengan desain cross sectional atau potong lintang, sampel penelitian diambil dari pasien yang melahirkan di RSUD Panembahan Senopati, data dikumpulkan dengan metode wawancara. Uji Chi square dan prevalence ratio dipakai untuk analisis statistika.

Hasil dan Pembahasan: Penelitian ini melibatkan 260 subyek, $161(61,92 \%)$ persalinan vaginal dan $99(38,08)$ SC. Total pengguna IUD pascasalin sebanyak 128 (49,23\%). Persalinan SC memiliki hubungan bermakna dengan penggunaan IUD pascasalin (p 0,000; PR 1,49; Cl 1,19-1,89). Faktor lain yang mempengaruhi penggunaan IUD pascasalin secara bemakna adalah riwayat penggunaan metode kontrasepsi jangka panjang (MKJP) sebelumnya (p 0,002; PR 1,68; Cl 1,38-2,06), adanya asuransi Jaminan Kesehatan Nasional (JKN) ( $\mathrm{p} 0,038 ;$ PR 1,71; Cl 1,04-2,80), dan konseling (p 0,000; PR 2,84; $\mathrm{Cl} 1,85-4,35)$. Alasan terbanyak subyek menolak penggunaan IUD pascasalin adalah takut efek samping (35\%).

Kesimpulan: Penggunaan IUD pascasalin lebih tinggi secara bermakna pada seksio sesarea dibandingkan persalinan vaginal. Faktor lain yang mempengaruhi penggunaan IUD pascasalin secara bermakna adalah riwayat penggunaan MKJP, adanya asuransi JKN dan konseling.
\end{abstract}

Kata Kunci: IUD pascasalin; metode persalinan; angka pemasangan; persalinan vaginal, SC 


\section{PENDAHULUAN}

Derajat kesehatan masyarakat salah satunya dapat dilihat dari indikator Angka Kematian Ibu (AKI). AKI adalah jumlah kematian ibu selama masa kehamilan, persalinan dan nifas yang disebabkan oleh kehamilan, persalinan, dan nifas atau pengelolaannya tetapi bukan karena sebab-sebab lain seperti kecelakaan atau terjatuh di setiap 100.000 kelahiran hidup. ${ }^{1}$

Pelayanan kontrasepsi menjadi salah satu upaya percepatan penurunan AKI melalui upaya pencegahan kehamilan, penundaan usia kehamilan dan menjarangkan kehamilan. Sasaran utama program KB adalah pada kelompok unmet need dan ibu pascasalin. Kehamilan yang tidak diinginkan pada ibu pascasalin akan dihadapkan pada dua hal yang sangat berisiko. Pertama, jika kehamilan diteruskan, maka kehamilan tersebut akan berjarak sangat dekat dengan kehamilan sebelumnya. Kedua, jika kehamilan diakhiri maka berpeluang untuk terjadinya komplikasi aborsi yang juga dapat berkontribusi terhadap kematian ibu. Sehingga KB pascasalin merupakan suatu upaya strategis dalam penurunan AKI. Riskesdas 2007 mencatat sebanyak $17 \%$ total kehamilan merupakan kehamilan yang tidak diinginkan (Mujiati, 2013). ${ }^{2}$ Sebuah studi secara global angka kehamilan yang tidak diinginkan sebesar 40\% dan di Asia sekitar 38 persen. ${ }^{3}$ (Sedgh et al., 2013).

Indikator prevalensi penggunaan kontrasepsi adalah CPR (Contraceptive Prevalence Rate = angka kesertaan ber-KB) dan unmet need (pasangan usia subur yang membutuhkan pelayanan KB namun tidak dapat melaksanakannya dengan berbagai alasan). Target nasional CPR pada tahun 2015 adalah sebesar 65.2\%, Age Specific Fertility Rate (ASFR), ASFR usia 15-19 tahun sebesar 30/1000 perempuan usia 15-19 tahun dan unmet need 5\%1 kedua indikator program KB ini masih jauh dari target. Hal ini patut diduga berkontribusi terhadap landainya penurunan $\mathrm{AKI}$, dimana program KB merupakan salah satu upaya penurunan AKI di bagian hulu. ${ }^{4,5}$

Pencapaian peserta KB aktif semua metode kontrasepsi yang diperoleh dari Profil Kesehatan Indonesia Kementerian Kesehatan tahun 2016 menyebutkan persentase akseptor Alat Kontrasepsi Dalam Rahim/AKDR atau Intra Uterine Device/IUD hanya $7,23 \%$, jauh di bawah suntikan yang mencapai $51,53 \%$ dan pil $23,17 \%$. cakupan KB pascasalin dan pasca keguguran dibandingkan dengan cakupan peserta KB baru masih sebesar 13,27 persen. Capaian tersebut juga masih didominasi oleh non MKJP (Metode Kontrasepsi Jangka Panjang) yaitu suntikan $(52,49 \%)$ dan pil $(18,95 \%)$, sementara capaian MKJP implan (8,08\%), IUD (14,06\%), MOW $(3,27 \%)$ dan $\operatorname{MOP}(0,02 \%) .^{5}$

Angka seksio caesarea (SC) meningkat secara signifikan setiap tahunnya. Penelitian South East Asia - Optimising Reproductive and Child Health in Developing countries (SEA-ORCHID) yang dilakukan di empat Negara di Asia tenggara meliputi Indonesia, Malaysia, Filipina dan Thailand pada tahun 2015 menunjukkan 27\% persalinan dilakukan melalui seksio sesarea dengan indikasi yang paling sering adalah riwayat SC sebesar $7 \%$, disproporsi kepala panggul (DKP) 6,3\%, malpresentasi 4,7\% dan gawat janin 3,3\%. Di Indonesia sendiri, angka seksio sesarea mencapai $29,6 \% .6$

Edukasi penggunaan IUD pascasalin pada SC mungkin lebih mudah karena pasien diminta untuk menunda kehamilan selanjutnya sampai dengan 2 tahun. Selain itu, IUD pascasalin pada SC memiliki angka ekspulsi yang jauh lebih rendah dibandingkan persalinan vaginal.

\section{METODE}

Penelitian ini merupakan penelitian analitik dengan desain cross sectional atau potong lintang, sampel penelitian diambil dari pasien yang melahirkan di RSUD Panembahan Senopati selama periode penelitian yang memenuhi kriteria inklusi dan eksklusi, data dikumpulkan menggunakan lembar bantu dengan metode wawancara.

Variabel bebas pada penelitian ini adalah metode persalinan, sedangkan variable tergantungnya adalah penggunaaan IUD pascasalin. Variabel luar yang diteliti adalah usia, pendidikan, status pekerjaan, penggunaan asuransi, paritas, 
perencanaan kehamilan, riwayat kontrasepsi sebelumnya, riwayat kontrasepsi gagal, konseling IUD pascasalin, pengetahuan tentang manfaat IUD pascasalin.

Analisis data yang digunakan adalah analisis univariat, bivariat, dan multivariate. Uji statistik yang digunakan untuk analisis bivariat adalah uji chi square. Uji statistik yang digunakan untuk analisis multivariat adalah uji regresi logistik.

\section{HASIL DAN PEMBAHASAN}

\section{Analisis Univariat}

Sebanyak 260 subyek penelitian tersebut, 161 $(61,92 \%)$ subyek melahirkan secara vaginal dan 99 $(38,08)$ subyek melahirkan secara seksio sesaria (SC). Usia terendah dari subyek penelitian ini adalah 17 tahun, dan usia tertinggi adalah 48 tahun. Rerata usia adalah 29,34 tahun. Total pengguna IUD pascasalin sebanyak $128(49,23 \%)$ subyek. Sisanya 132 (50,77\%) tidak memilih IUD pascasalin. Alasan terbanyak (35\%) yang dikemukakan oleh subyek yang tidak menggunakan IUD pascasalin adalah karena takut efek samping. Karakteristik subyek penelitian dapat dilihat pada tabel 1 .

\section{Analisis Bivariate}

Hasil analisis variabel utama dapat dilihat pada table 2 dan 3. Pada penelitian didapatkan perbedaan secara bermakna penggunaan IUD pascasalin pada seksio sesarea dibandingkan persalinan vaginal dengan nilai $p \quad 0,001$. Penggunaan IUD pascasalin tidak berbeda bermakna pada persalinan seksio sesarea elektif atau emergensi ( $p 0,207)$ dan juga tidak bermakna $(p 0,617)$ pada kelompok dengan riwayat seksio sesarea sebelumnya atau tanpa riwayat sebelumnya.
Tabel 1. Karakteristik Subjek Penelitian

\begin{tabular}{|c|c|c|c|}
\hline No. & Karakteristik & Jumlah & Persen \\
\hline \multirow[t]{3}{*}{1} & Metode persalinan & & \\
\hline & Seksio sesarea & 99 & 38,08 \\
\hline & Vaginal & 161 & 61,92 \\
\hline \multirow[t]{3}{*}{2} & Penggunaan IUD pascasalin & & \\
\hline & Ya & 128 & 49,23 \\
\hline & Tidak & 132 & 50,77 \\
\hline \multirow[t]{3}{*}{3} & Usia & & \\
\hline & $<20 \&>35$ tahun & 72 & 27,70 \\
\hline & 20-35 tahun & 188 & 72,30 \\
\hline \multirow[t]{3}{*}{4} & Paritas & & \\
\hline & Primigravida & 101 & 38,85 \\
\hline & Multigravida & 159 & 61,15 \\
\hline \multirow[t]{3}{*}{5} & Pendidikan & & \\
\hline & $\leq 9$ tahun & 43 & 16,54 \\
\hline & $>9$ tahun & 217 & 83,46 \\
\hline \multirow[t]{3}{*}{6} & Agama & & \\
\hline & Islam & 253 & 97,31 \\
\hline & Bukan Islam & 7 & 2,69 \\
\hline \multirow[t]{3}{*}{7} & Status pekerjaan & & \\
\hline & Bekerja & 105 & 40,38 \\
\hline & Tidak Bekerja & 155 & 59,62 \\
\hline \multirow[t]{3}{*}{8} & Perencanaan kehamilan & & \\
\hline & Direncanakan & 243 & 93,46 \\
\hline & Tidak & 17 & 6,54 \\
\hline \multirow[t]{3}{*}{9} & Riwayat gagal kontrasepsi & & \\
\hline & Pernah & 21 & 8,08 \\
\hline & Tidak Pernah & 239 & 91,92 \\
\hline \multirow[t]{4}{*}{10} & Penggunaan kontrasepsi seb & lumnya & \\
\hline & Belum pernah & 97 & 37,31 \\
\hline & MKJP & 46 & 17,69 \\
\hline & Non MKJP & 117 & 45,00 \\
\hline \multirow[t]{3}{*}{11} & Penggunaan asuransi & & \\
\hline & JKN & 192 & 73,85 \\
\hline & Non JKN & 68 & 26,15 \\
\hline \multirow[t]{3}{*}{12} & Pernah konseling & & \\
\hline & Pernah & 203 & 78,07 \\
\hline & Tidak Pernah & 57 & 21,93 \\
\hline \multirow[t]{3}{*}{13} & Pengetahuan tentang manfa & & \\
\hline & Tahu & 203 & 78,07 \\
\hline & Tidak Tahu & 57 & 21,93 \\
\hline \multirow[t]{3}{*}{14} & Status pernikahan & & \\
\hline & Menikah & 258 & 99,2 \\
\hline & Tidak Menikah & 2 & 0,8 \\
\hline
\end{tabular}


Table 2. Hasil Uji Bivariat antara Metode Persalinan dan Penggunaan IUD Pascasalin

\begin{tabular}{|c|c|c|c|c|c|c|c|}
\hline \multirow{2}{*}{ Metode Persalinan } & \multicolumn{4}{|c|}{ Penggunaan IUD } & \multirow{2}{*}{ Total } & \multirow{2}{*}{$\begin{array}{c}\text { PR } \\
(95 \% \mathrm{Cl})\end{array}$} & \multirow{2}{*}{$p$} \\
\hline & Ya & $\%$ & Tidak & $\%$ & & & \\
\hline Seksio sesarea & 69 & 69,70 & 30 & 30,30 & 99 & 1,902 & 0,000 \\
\hline Vaginal & 59 & 36,65 & 102 & 63,35 & 161 & $(1,494-2,420)$ & \\
\hline
\end{tabular}

Tabel 3. Hasil Uji Bivariate antara Riwayat dan Jenis SC terhadap Penggunaan IUD Pascasalin

\begin{tabular}{|c|c|c|c|c|c|c|c|c|}
\hline & & \multicolumn{4}{|c|}{ Penggunaan IUD pascasalin } & \multirow{3}{*}{$p$} & \multirow{3}{*}{ PR } & \multirow{3}{*}{$\mathrm{Cl} 95 \%$} \\
\hline & & \multicolumn{2}{|c|}{ Ya } & \multicolumn{2}{|c|}{ Tidak } & & & \\
\hline & & $\mathbf{n}$ & $\%$ & n & $\%$ & & & \\
\hline \multirow{2}{*}{$\begin{array}{l}\text { Riwayat seksio sesarea } \\
\text { sebelumnya }\end{array}$} & Pernah & 25 & $78.1 \%$ & 7 & $21.9 \%$ & \multirow[t]{2}{*}{0,207} & \multirow[t]{2}{*}{0,841} & \multirow[t]{2}{*}{$0,65-1,08$} \\
\hline & Belum pernah & 44 & $65.7 \%$ & 23 & $34.3 \%$ & & & \\
\hline \multirow[t]{2}{*}{ Jenis seksio sesarea } & Emergensi & 40 & $67.8 \%$ & 19 & $32.2 \%$ & \multirow[t]{2}{*}{0,617} & \multirow[t]{2}{*}{0,935} & \multirow[t]{2}{*}{$0,72-1,21$} \\
\hline & Elektif & 29 & $72.5 \%$ & 11 & $27.5 \%$ & & & \\
\hline
\end{tabular}

Pengaruh variabel luar terhadap penggunaan IUD pascasalin dapat dilihat pada tabel 4. Variabelluar yang secara bermakna meningkatkan penggunaan IUD pascasalin adalah paritas multigravida, riwayat penggunaan kontrasepsi sebelumnya, adanya asuransi, pemberian konseling dan pengetahuan tentang manfaat IUD pascasalin. Untuk mencari variabel mana yang paling berpengaruh terhadap angka penggunaan IUD pascasalin dilakukan analisis multivariat yang dapat dilihat pada tabel 5 .

Tabel 4. Pengaruh Variabel Luar terhadap Penggunaan IUD Pascasalin

\begin{tabular}{|c|c|c|c|c|c|c|c|}
\hline \multirow{2}{*}{ Variabel } & \multicolumn{4}{|c|}{ Penggunaan IUD } & \multirow{2}{*}{ Total } & \multirow{2}{*}{$\begin{array}{c}\text { PR } \\
(95 \% \mathrm{Cl})\end{array}$} & \multirow{2}{*}{$p$} \\
\hline & Ya & $\%$ & Tidak & $\%$ & & & \\
\hline \multicolumn{8}{|l|}{ Usia } \\
\hline$<20 \&>35$ tahun & 32 & 44,4 & 40 & 55,60 & 72 & 0,863 & 0,339 \\
\hline 20-35 tahun & 96 & 51,1 & 92 & 48,9 & 188 & $(0,65-1,17)$ & \\
\hline \multicolumn{8}{|l|}{ Pendidikan } \\
\hline$\leq 9$ tahun & 24 & 55,81 & 19 & 44,19 & 43 & 1,165 & 0,345 \\
\hline$>9$ tahun & 104 & 47,93 & 113 & 52,07 & 217 & $(0,863-1,572)$ & \\
\hline \multicolumn{8}{|l|}{ Status pekerjaan } \\
\hline Bekerja & 57 & 54,3 & 48 & 45,7 & 52 & 1,18 & 0,180 \\
\hline Tidak Bekerja & 71 & 45,8 & 84 & 54,2 & 208 & $(0,93-1,51)$ & \\
\hline \multicolumn{8}{|l|}{ Penggunaan asuransi } \\
\hline $\mathrm{JKN}$ & 102 & 53,1 & 90 & 46,9 & 192 & 1,38 & 0,035 \\
\hline Non JKN & 26 & 38,81 & 42 & 61,19 & 68 & $(1,04-1,93)$ & \\
\hline \multicolumn{8}{|l|}{ Paritas } \\
\hline Multigravida & 91 & 57,23 & 68 & 42,77 & 159 & 1,56 & 0,001 \\
\hline Primigravida & 37 & 36.63 & 64 & 63,37 & 101 & $(1,17-2,09)$ & \\
\hline \multicolumn{8}{|c|}{ Perencanaan kehamilan } \\
\hline Direncanakan & 121 & 49,80 & 122 & 50,20 & 243 & 1,21 & 0,492 \\
\hline Tidak & 7 & 41,20 & 10 & 58,80 & 17 & $(0,67-2,16)$ & \\
\hline
\end{tabular}




\begin{tabular}{|c|c|c|c|c|c|c|c|}
\hline \multirow{2}{*}{ Variabel } & \multicolumn{4}{|c|}{ Penggunaan IUD } & \multirow{2}{*}{ Total } & \multirow{2}{*}{$\begin{array}{c}\text { PR } \\
(95 \% \mathrm{Cl})\end{array}$} & \multirow{2}{*}{$p$} \\
\hline & Ya & $\%$ & Tidak & $\%$ & & & \\
\hline \multicolumn{8}{|c|}{ Penggunaan kontrasepsi sebelumnya } \\
\hline \multirow[t]{2}{*}{ MKJP } & 36 & 78,26 & 10 & 21,74 & 46 & 2,449 & 0,001 \\
\hline & & & & & & $(1,76-3,39)$ & \\
\hline \multirow[t]{2}{*}{ Non-MKJP } & 61 & 52,14 & 56 & 47,86 & 117 & 1,631 & 0,003 \\
\hline & & & & & & $(1,16-2,28)$ & \\
\hline Belum Pernah & 31 & 31,96 & 66 & 68,04 & 97 & pembanding & \\
\hline \multicolumn{8}{|c|}{ Riwayat gagal kontrasepsi } \\
\hline Pernah & 12 & 57,10 & 9 & 42,90 & 21 & 1,12 & 0,449 \\
\hline Tidak Pernah & 116 & 48,50 & 123 & 51,50 & 239 & $(0,79-1,74)$ & \\
\hline \multicolumn{8}{|l|}{ Pernah konseling } \\
\hline Pernah & 116 & 57,1 & 87 & 42,9 & 203 & 2,71 & 0.000 \\
\hline Tidak Pernah & 12 & 21,1 & 45 & 78,9 & 57 & $(1,62-4,55)$ & \\
\hline \multicolumn{8}{|c|}{ Pengetahuan tentang manfaat } \\
\hline Tahu & 116 & 57,1 & 87 & 42,9 & 203 & 2,71 & 0,000 \\
\hline Tidak Tahu & 12 & 21,1 & 45 & 78,9 & 57 & $(1,62-4,55)$ & \\
\hline
\end{tabular}

Tabel 5. Analisis Multivariat terhadap Angka Penggunaan IUD Pascasalin Konversi OR ke PR

\begin{tabular}{|c|c|c|c|c|}
\hline Variabel & PR & Cl $95 \%$ & Nilai $p$ & $\mathbf{R}^{2}$ \\
\hline \multicolumn{5}{|l|}{ Metode Persalinan } \\
\hline Seksio sesarea & 1,49 & $1,19-1,89$ & 0,000 & \\
\hline Vaginal & 1 & & & \\
\hline \multicolumn{5}{|c|}{ Kontrasepsi Sebelumnya } \\
\hline MKJP & 1,68 & $1,38-2,06$ & 0,002 & \\
\hline Non-MKJP & 1 & & & 0,271 \\
\hline Belum Pernah & 1 & & & \\
\hline \multicolumn{5}{|l|}{ Pernah Konseling } \\
\hline Pernah & 2,84 & $1,85-4,35$ & 0,000 & \\
\hline Tidak Pernah & 1 & & & \\
\hline \multicolumn{5}{|c|}{ Penggunaan asuransi } \\
\hline JKN & 1,71 & $1,04-2.80$ & 0,038 & \\
\hline Non JKN & 1 & & & \\
\hline
\end{tabular}

Berdasarkan hasil analisis regresi logistik dan konversi odds ratio (OR) menjadi prevalence ratio $(P R)$, adanya pemberian konseling mempunyai hubungan yang kuat dengan penggunaan IUD yakni dengan nilai PR tertinggi, yakni 2,84. Kemudian persalinan seksio sesarea dengan nilai PR sebesar 1,49. Subyek dengan persalinan seksio sesarea memiliki kemungkinan sebesar 1,49 kali memilih IUD sebagai alat kontrasepsi dibandingkan persalinan vaginal.
Nilai $R^{2}$ sebesar 0,271 menunjukkan bahwa persalinan seksio sesarea, adanya riwayat penggunaan MKJP, pernah mendapatkan konseling dan adanya pembiayaan JKN menyumbang kemungkinan subyek memilih IUD pascasalin sebesar $27,1 \%$.

Metode persalinan memiliki hubungan bermakna dengan penggunaan IUD pascasalin $(p=0,000)$. Subyek pada kelompok persalinan seksio sesarea lebih banyak menggunakan IUD sebanyak 
69,70\% dibandingkan dengan subyek pada kelompok persalinan vaginal sebanyak $36,65 \%$ (PR 1,49; Cl 1,19-1,89). Hasil ini serupa dengan penelitian oleh Tang et al. (2014) bahwa penggunaan IUD lebih banyak pada klien dengan persalinan seksio sesarea sebanyak $38,7 \%$ dibandingka

vaginal sebanyak $28,8 \%$ tetapi tidak bermakna secara signifikan (p 0,08 RR 1,8 Cl 0,9-3,6). ${ }^{7}$ Kelompok subyek dengan persalinan seksio sesarea lebih mudah menerima IUD pascasalin karena adanya motivasi untuk menunda kehamilan selanjutnya minimal sampai dengan 2 tahun. Pada analisis lebih lanjut, subyek yang memiliki riwayat seksio sesarea sebelumnya lebih banyak menggunakan IUD pascasalin $(78,1 \%)$ dibandingkan subyek yang tidak memiliki riwayat seksio sesarea sebelumnya $(65,7 \%)$ tetapi perbedaan ini tidak bermakna ( $p$ 0,207; PR 0,841; Cl 0,653-1,082). Hal ini karena motivasi menggunakan metode kontrasepsi jangka panjang menjadi lebih tinggi pada pasien yang memiliki riwayat persalinan seksio sesarea sebelumnya karena meningkatnya risiko komplikasi pada kehamilan berikutnya.

Subyek dengan persalinan seksio sesarea yang dilaksanakan secara elektif menunjukkan penggunaan IUD pascasalin lebih tinggi $(72,5 \%)$ dibandingkan pada kelompok subyek dengan persalinan seksio sesarea emergensi (67,8\%) tetapi tidak berbeda bermakna ( $p 0,617$; PR 0,935; $\mathrm{Cl}$ 0,721-1,212). Hal ini karena tindakan elektif memungkinkan pemberian konseling kontrasepsi pascasalin yang cukup.

Faktor-faktor lain yang meningkatkan pemasangan IUD pascasalin secara bemakna adalah adalah riwayat penggunaan kontrasepsi jangka panjang (MKJP) sebelumnya, adanya asuransi JKN, pemberian konseling dan pengetahuan tentang manfaat IUD pascasalin. Peneltian oleh Oduyebo et al (2019) menunjukkan prevalensi penggunaan MKJP pascasalin sangat rendah pada pasien yang tidak memiliki asuransi (AOR 0,73 $\mathrm{Cl} 0,55-0,96) .{ }^{8}$ Hasil tersebut mendukung penelitian ini dimana subyek yang menggunakan JKN sebagai pembiayaan cenderung menggunakan IUD pascasalin secara bermakna dibandingkan subyek tanpa kepesertaan JKN (p 0,035; OR 1,39; Cl 1,04-1,93). Sebanyak $61,19 \%$ subyek yang tidak memiliki asuransi (pasien umum) pada akhirnya tidak menggunakan kontrasepsi pascasalin.

Konseling dan pengetahuan subyek juga mempengaruhi penggunaan IUD pascasalin secara signifikan ( 0,000 ; PR 2,71; Cl 1,62-4,55; p 0,000; PR 2,71; $\mathrm{Cl} 1,62-4,55)$. Hal ini sejalan dengan penelitian Mahendra (2017) yang menyimpulkan wanita usia subur (WUS) 2,3 kali lebih besar menggunakan MKJP ila melibatkan suami atau tenaga kesehatan dalam pengambilan keputusan dibandingkan dengan WUS yang memutuskan sendiri (OR 2,3;2,02,7). ${ }^{9}$ Akan tetapi terdapat kemungkinan 3 kali lebih besar penggunaan MKJP apabila WUS itu sendiri tidak dilibatkan dalam pengambilan keputusan $(\mathrm{OR}=3,1 ; 2,3-4,1)$. Hal ini juga serupa dengan Cochrane review oleh Arrowsmith ME, Aicken CRH, Saxena S, dan Majeed A (2012) yang menunjukkan bahwa konseling dan adanya sistem rujukan komunitas meningkatkan penggunaan IUD dua kali lebih banyak (OR 2.00; 95\% Cl 1.4-2.85). ${ }^{10}$

Setelah dilakukan analisis multivariat dengan regresi logistik dan konversi dari OR ke PR, untuk mengetahui variabel mana yang paling berpengaruh terhadap angka pemasangan IUD pascasalin, adanya konseling kepada subyek mempunyai hubungan yang kuat dengan penggunaan IUD dengan nilai prevalence ratio tertinggi yakni 2,84. Metode persalinan juga berhubungan bermakna dengan penggunaan IUD pascasalin dengan nilai prevalence ratio sebesar 1,49 . Subyek dengan persalinan SC memiliki kemungkinan sebesar 1,49 kali memilih IUD pascasalin sebagai alat kontrasepsi dibandingkan wanita yang melahirkan secara vaginal. Faktor metode persalinan abdominal, pengalaman penggunaan kontrasepsi jangka panjang (MKJP) sebelumnya memiliki nilai $R^{2} 0,271$, artinya faktorfaktor tersebut menyumbang $27,1 \%$ kemungkinan subyek memilih menggunakan IUD pascasalin.

\section{KESIMPULAN DAN SARAN}

Penggunaan IUD pascasalin pada seksio sesarea lebih tinggi secara bermakna dibandingkan persalinan vaginal. Subjek dengan persalinan seksio sesarea memiliki kemungkinan sebesar 1,49 kali memilih IUD pascasalin sebagai alat kontrasepsi dibandingkan wanita yang melahirkan secara vaginal. Faktor lain 
yang meningkatkan penggunaan IUD pascasalin secara bemakna adalah riwayat penggunaan kontrasepsi jangka panjang (MKJP) sebelumnya, adanya asuransi JKN, dan adanya konseling.

\section{SARAN}

Penggunaan IUD pascasalin dapat ditingkatkan dengan mengoptimalkan faktor-faktor yang dapat diubah seperti meningkatkan cakupan JKN atau membebaskan biaya pemasangan kontrasepsi pascasalin untuk semua pasien dan menggalakkan kembali konseling kontrasepsi pascasalin pada kunjungan ANC. Perlu dilakukan penelitian dengan sampel dari beberapa rumah sakit di wilayah Bantul agar lebih menggambarkan pencapaian IUD pascasalin di Bantul secara lebih baik.

\section{DAFTAR PUSTAKA}

1. Kementrian Kesehatan RI. Kesehatan Reproduksi. Buletin Jendela Data dan Informasi Kesehatan.Vol 2. Jakarta. 2013.

2. Kementrian Kesehatan RI. Profil Kesehatan Indonesia tahun 2016. Jakarta. 2016.

3. Sedgh, G., Singh, S., Hussain, R. Intended and Unintended Pregnancies Worldwide in 2012 and Recent Trends.Studies in Family Planning. 45[3]: 301-314. 2014.

4. BKKBN. Laporan Kinerja Instansi Pemerintahan (LAKIP) BKKBN. Jakarta. 2016.
5. Mujiati, I. Pelayanan KB Pasca Persalinan dalam Upaya Mendukung Percepatan Penurunan Angka Kematian Ibu. Buletin Jendela Data dan Informasi Kesehatan. 2:11-16. 2013.

6. Cowman, W., Hardy-Fairbanks, A., Endres, J., and Stockdale C.K. 2013.A select issue in the postpartum period: contraception. Proc Obstet Gynecol. 3(2):15 Festin, Mario R. et al. The SEA-ORCHID Study group. Caesarean Section in four South East Asian countries: reasons for, rates, associated care practices and health outcomes. BMC Preganancy and Childbirth. 2009.

7. The acquire project end of project report to USAID. Submitted to Office of Population and Reproductive Health Bureau for Global Health United States Agency for International Development Washington, D.C. 2008.

8. Oduyebo T, Zapata LB, Boutot ME, et al. Factors associated with postpartum use of longacting reversible contraception. Am J Obstet Gynecol 2019;XX:XX. 0002-9378/\$36.00 Published by Elsevier Inc. https://doi.org/10.1016/j.ajog.2019.03.005

9. Mahendra, I.G. A.A. Peran Pengambil Keputusan dalam Pemilihan Metode Kontrasepsi Jangka Panjang di Indonesia (Analisis Data Performance Monitoring and Accountability 2020). Tesis. Universitas Gadjah Mada. 2017.

10. Arrowsmith ME, Aicken $\mathrm{CRH}$, Saxena S, MajeedA. Strategies for improving the acceptability and acceptance of the copper intrauterine device (Review). Cochrane Data base of Systematic Reviews 2012, Issue 3. Art. No: CD008896. DOI: 10.1002/14651858.CD008896. pub2. 